\title{
Attention and the Subject of Depiction Some Remarks on Husserl's Approach to the Function of Attention in Phantasy, Image Consciousness and Pictorial Experience
}

\author{
Andrea Scanziani \\ Università degli Studi di Milano \\ andrea.scanziani@yahoo.com
}

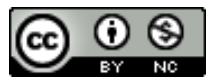

\begin{abstract}
This study aims at exposing the phenomenological description of attention as presented by Husserl in his 1904-05 Göttingen-lecture Principal Parts of the Phenomenology and Theory of Knowledge, in its relevance for the study of so-called "intuitive representations", that is, phantasy and image-consciousness. Starting with the exposition of the fundamental traits of the intentional theory of attention, this study discusses the definition of attention in the terms of meaning [Meinen] and interest, which allows it to become an encompassing modification of all kinds of lived experiences that does not imply an alteration of their act-character (Husserl, 2004: 73). We refer to this character of attention as "plasticity". In what follows, the study underlines these two definitions of attention and their importance for the understanding of phantasy and imageconsciousness. Both kinds of re-presentations will be described stressing the role of attention in the "structuring" of the intentional act and in its affective basis. Finally, the study deals more specifically with the complex description of image consciousness from the viewpoint of the attentional meaning of the image subject.
\end{abstract}

Keywords: Husserl, Attention, Phantasy, Image-consciousness

ISSN: 0874-9493 (print) / ISSN-e: 2183-0142 (online)

DOI: $10.2478 /$ phainomenon-2019-0005

(C) 2019 Scanziani. This is an open access article licensed under the Creative Commons Attribution-NonCommercial-NoDerivs License (http://creativecommons.org/licenses/by-nc$\mathrm{nd} / 3.0 /)$. 


\section{Introduction}

Generally speaking, considering attention philosophically, or psychologically, means to investigate the different phenomena of special awareness and responsiveness to stimuli within the sphere of perception. In fact, philosophy and psychology have often approached attention from the viewpoint of human responsiveness to external stimuli, the voluntary control over the coordination and orientation of sense organs, and also its role by the direction and coherence of the focus of our conscious-life ${ }^{1}$. Around the end of the 19th century, philosophers and psychologists like James, Külpe, Titchener, and Wundt, were among the most important, and they have proposed various accounts of attention, even taking the contribution of the recently-born experimental psychology into consideration. The token path has linked scientific investigations on attention to the study of perception and the fundamental kind of conscious experiences (interest, volition, judgment etc.). The interesting yet challenging aspect of such investigation is the fact that attention, somehow, cuts across almost all the psychological taxonomy of the cognitive and sensitive faculty. It is scientifically relevant, in this sense, that psychological studies on attention and its function in imaging and image consciousness around 1900 (pictorial or not) have heavily relied on their dependence upon perception and sensation $^{2}$. This assumption has strongly influenced and stimulated psychological studies on attention and visual imagery (Clark, 1916: 461), and also some more specific studies on the cognitive and meaning function of images on the basis of attentive consciousness. ${ }^{3}$

For its part, phenomenology does follow a path of developing an intentional theory of attention, that is, a description of attention ruled within the general theory of the intentionality of consciousness. Under different concepts, such as, "the regard to", the "turning towards" and the slightly metaphorical reference to the "ray of attention", Husserl refers to attentive consciousness in his main works on phenomenology ${ }^{4}$. Besides his first attempt in Philosophy of Arithmetic (1891 - 2), where attention already plays a role as a synthetic act by

1 Cf. Mole, 2011: 5ff.

2 See, for example, Külpe, 1902: $508 \mathrm{ff}$.

$3 C f$. for example, Betts, 1909: 41

4 See Husserl (1989: 112-113) and (1998: 257). 
the formation of complex and categorial objects, it is between 1898 and 19045 that Husserl strongly develops the main aspects of his views on attention ${ }^{5}$. His research is coupled with the phenomenological description of intentional acts, namely the different forms of intentional consciousness and their objects. Therefore, Husserl outlines a phenomenology of attention and a unitary definition of it in the sphere of the most basic experiences, which phantasy and image-consciousness, as a form of intentional act, also belong to (Husserl, 2004: 6).

This approach paves the way for a study of attention, which does not reduce it and its active responsiveness to mere qualitative differences by pure content of sensation. Surely, even Husserl's approach to attention is, to a certain extent, anchored to his description of perception as the fundamental kind of intentional act. The starting point through perception seems to be justified, on the one hand, due to the "original consciousness" and the close likeness in structure of perception with respect to other forms of intentional acts (Husserl, 2001c: 4; 2004: 7); and on the other, because of the "founding function" pointed out by Husserl with respect to perception. All the modes of "intuitive re-presentation" [anschauliche Vergegenwärtigung], that is; memory, phantasy, imageconsciousness etc., are founded on a presentation of perception (Husserl, 2005: 93 - 94). These founding relationships and likeness may allow for the implementation of a description resulting from perception to the realm of all intuitive re-presentations. Although it may appear arguable that a phenomenology of attention would help to shine light on such kinds of lived experiences, in around 1900 Husserl himself offers an early example of description of how the "intending [meinende] turning-towards" of attention objectively articulates a phantasy representation (Husserl, 1991: 165f). Moreover, Husserl felt the need for an accurate study of "attentional modifications" in memory. Such modifications do not affect the character of memory act while maintaining similarities in the function of attention within the perceptual sphere (Husserl, 2004: 294 - 5). For its part, Husserl's description of image-consciousness in the 1904-5 lecture Principal Parts of the Phenomenology and Theory of Knowledge makes an abundant reference to the

5 Cf. Husserl (2004: 86 f). On Husserl's work on attention and perception between 1898 and 1904-5, see, Vongehr (2010: 17-30); Depraz (2009: 7-62). 
meaning [das Meinen] of the subject in image-consciousness ( $C f$. for example, Husserl 2005: 39) ${ }^{6}$. In this sense it is of keen interest to interpret the proper function and the role played by attention in the sphere of phantasy and image consciousness from the viewpoint of phenomenology.

Therefore, in what follows I will attempt to present the role of attention in phantasy and image consciousness in its guidelines more specifically, that is, to stress the role played by two of the fundamental aspects of attention as phenomenologically described by Husserl in his 1904-5 lectures on the Principal Parts, i.e., meaning (or intending) and interest ${ }^{7}$. In fact, according to Husserl, the reference through meaning to their object and subject on the basis of one or more apprehensions is fundamental for phantasy and image consciousness. The fact that the pictorial experience is partially based, on the one hand, on a peculiar conflict promoted by meaning, and, on the other, on a specific form of interest, gives us even the possibility to posit the phenomenology of attention also in the phenomenology of aesthetic experience.

This exposition will follow three main steps. First, I will briefly outline the basic features of attention as in its definition as meaning and interest; second, by exposing such basic and fundamental traits I will stress an important characteristic of attention, connected to its definition, which can be called the "plasticity of attention"; third, I will point out how Husserl describes attention in the case of two kinds of lived experiences less investigated by psychology and philosophy under an attentive consciousness viewpoint, i.e., phantasy and image-consciousness, and by considering the two cases it will be possible to stress the relevant function of attention for the phenomenological description of such lived experiences, which I may call the "structuring of attention". Having followed such steps, some conclusions will be presented. Both the plasticity of attention and the structuring operated by it are fundamental

6 Notoriously, the four parts of Husserl's 1904-5 Lecture have been published separately. The first two Parts "On Perception" and "On Attention, Specific Meaning" in Husserl (2004: 3-122); the third Part on "Phantasy, Image Consciousness and Memory" in Husserl (2005: 1-116); and the last "On The Phenomenology of The Consciousness of Internal Time", in Husserl (1991: 3-104).

7 The German word meinen/das Meinen is usually translated with meaning or intending and we will follow this translation. The German word will be added where needed. 
elements in Husserl's phenomenology of phantasy and image consciousness, while both depend on the traits recognised by Husserl as defining attention. Therefore, understanding the role that attention plays in image-consciousness adds important elements in Husserl's phenomenology of image and aesthetic experience.

\section{Fundamental traits of Husserl's early concept of attention}

The first edition of Logical Investigations was published in 1900, where Husserl presents, among other topics, some insights into the problem of attention and attentional consciousness. After about twelve years, in the second edition of his Investigations, the core paragraphs that deal specifically with attention are slightly but importantly modified by Husserl. What emerges from this study is the unitary notion of attention, which is "(...) so wide that it doubtless embraces the whole field of intuitive and cogitative meaning [Meinen], the field of presentation in a well-defined but sufficiently wide sense, which comprehends both intuition and thought" (Husserl, 2001: 275, modified). The ever-problematic scope of the concepts allows Husserl to define attention in the sense of "consciousness of something" (Husserl, 2001: 275) and, therefore, to outline the intentional theory of attention, i.e., a description of attention rooted in the definition of consciousness and its intentionality. In the years of its initial development (1898-1905), this theory implicates the definition of attention "in the terms of meaning and interest", which are, for Husserl, two different yet related aspects of the same phenomena (Husserl, 2004: 114, 117, 119). In fact, Husserl notes that "the sense of speaking about meaning appears to have a relation to attention, or even to express something identical with it. That which is attended is what is specially intended [Gemeinte], in opposition to what it is unattended" (Husserl, 2004: 73). Attention and meaning may not be identical terms, but the meaning evidently represents an aspect of attentive consciousness, which allows a phenomenological analysis of concepts that are "deeply connected" to each other. In this sense, the study of attention in relation to the analysis of the intentional act links the description of attentive consciousness to apprehension 
[Auffassung], quality, and intention (Cf. Husserl, 2004: 73) $)^{8}$.

For the sake of our exposition, it must be stressed that in around 1905, meaning and apprehension are not to be identified, for the former "represents a higher function, which is nothing without apprehension, but itself not apprehension". The meaning "hovers over" the apprehension and articulates it, allowing "partial apprehensions and identifications" to take place, and even "the possibility of relations, comparisons, complex formations?" etc. (Husserl, 2004: 81). By means of such "wandering" of meaning, a certain "change in that what is objective in apprehension" results. This aspect is important in order to understand the role played by attention as regards presentations (e.g. perception) and re-presentation (e.g. phantasy). Therefore, the main functions of meaning must be initially introduced. First of all, it confers an apprehension of a certain autonomy or specific relevance, and by that an object is now attentively given for itself. Furthermore, Husserl defines meaning as a "preferential and formative [gestaltend] factor in the phenomenon of perception" (Husserl, 2004: 116, 72f). Both functions operate selectively within the sphere of givenness, also structuring such a sphere without permanently excluding or erasing other contents (Husserl, 2004: 283). The meaning introduces a preference among contents and acts, while it can maintain another object or "whatever part or moment of such an object" in a "complex phenomenon of meaning" (Husserl, 2004: 117). Therefore, the meaning may represent an "objectifying" aspect of attention". Connected with the meaning is the special clarity and distinctness of the act, even if not necessarily of the act object $^{10}$. Still, by the clear presentation of the object in the specific turningtowards of the meaning it is the object that results "illuminate", "raised from the obscurity" (Husserl, 2004: 121).

While the preferential function exposed emphasises the closeness of the meaning to attention, Husserl also defines the meaning as "intending [Intendieren] in the more proper sense" (Husserl, 2004: 68). Generally speaking, the reference to intending in the sense of meaning helps Husserl to

8 On the definition of attention in relation to intentionality and apprehension, see Bégout (2007: $15 \mathrm{f})$.

9 Cf. for example, Husserl (2004: 118 f); Husserl (1988: 338 f).

$10 C f$. Breyer (2011: 152). 
exclude the kind of lived-experiences which are intentional without being attentional, like retentions and protentions. The unity of apprehensional intention is, in fact, a complex of intentions, determined and undetermined, that constitute the entire experiential field (Husserl, 2001b: 211). The complex of intentions determines and codetermines, for example, on the basis of the past experience, that will take the focus of attention and the possible special perceptions with their specific meaning [Sondermeinung]. At the same time, it defines the foreground of experience and the background to be explored (Husserl, 2004: 69). The complex intention, which can be fulfilled, or not, says Husserl, "is not the background of the attention, but of the apprehension" (Husserl, 1991: 316). In this sense, attention "circumscribes" an intention in maintaining the co-intended. The special meaning in its "singling out" [herausheben], in its delimiting function, is not yet accounted for the quality of the act (Husserl, 2004: 74, 83). In this sense, "attention is not intention [Intention]" as regards an act of taking position, or even a new act on its own, where a doxic position is explicitly taken in respect of the object (Husserl, 1984: 250). Attention is, starting from 1905 on, but a modification of an act, which superimposes on the unity of intention; it fuses with it.

In the same Principal Parts Husserl also defines attention as interest. Generally speaking, "interest appears (...) as an act of such class comprehended under the title of meaning lived-experiences; especially, it appears closely related with kinds of acts like expectation, desire, and will, among others" (Husserl, 2004: 104). Interest connects attention to affection. When something affects us from the field of less attentive contents of experience, an interest in "theoretical" sense is awakened as a form of meaning act, which is described as "a complex act of (...) tension and release" (Husserl, 2004: 104). With the notion of tension Husserl establishes a connection between interest and intention [Intention]. The latter aims at the proper givenness of the object and is dominated by a graduation of partial release and new tension aiming at evernew givennesses (Husserl, 2004: 104 - 5). Therefore, attention as interest is defined as the "motor of the cognitive process". At the same time, it differs from meaning due to its gradualness of fulfilment, and due to the fact that it is based on feelings [Gefühlsbasis] with differences in intensity, a characteristic not shared by meaning, as we will discuss in more detail below (Husserl, 2004: $118-9)$. 
Eventually, in 1906 the intentional theory of attention is embedded by Husserl in a plan for a phenomenological "critique of reason", and that by relying on the earlier "attempts made for a phenomenology of attention" (Husserl, 1956: 298). A well-known result of such a theory is the definition of attention in the metaphorical terms "regard to" or "look into" and the spatialinspired description of the focus of attention and its surroundings which are less and less attentive in the term "ray" (Husserl, 1998: 225) ${ }^{11}$. This ray actually implies a "halo", which is the result of the "focalisation" of attention and, conceives, as a counterpart, a focalisation and "diffusion" of interest (Husserl, 2004: 172). In the same work where the reference to such illustration of attention appears, mainly the volumes of Ideas, Husserl finally refers to attention as a "fundamental species of intentive modification", and also, as a modification of acts in the sense of activity (Husserl, 1998: 71-72, 226). Thus, this definition opens up to the double yet correlate definition of attention: a general definition in terms of a fundamental modification to nearly all intentional acts; and a specific one, in the terms of meaning and interest. Husserl's definition of attention also encompasses the focus of our actual experience and its less and less attentive surroundings, and by means of that, it also connects attention with the explicitly "cogitative" form of acts (Husserl, 1998: 200, 225). Corresponding to the active sphere of attention is possible to indicate the passively constituted horizon of experience, which is simultaneously interwoven with all the possible active developments of an explicitly egological life ${ }^{12}$. Attention thus operates a certain selection of objects and characteristics belonging to the objects by the prejudice of certain others. By means of such selecting and prejudicing power, the results were that the objects of attention "became conscious in a special way" (Husserl, 2004: 90). Notoriously, Husserl describes the sphere of attention in its different articulations and levels of constitution, recurring to the aforementioned representation of the ray of attention with its less and less attentive fringe ${ }^{13}$. In this sense, Husserl uses the distinction between the focus of consciousness and

$11 C f$. Marbach (1974: 150-203), and on the genesis of Husserl's theory of attention pp. $218-246$.

$12 C f$. Wehrle (2010: $77 \mathrm{f})$.

13 An early work on this topic is to be found in Husserl (1979: $277 \mathrm{f}$ ). 
the so called "field of view" of consciousness, where the contents are pushed into the background or secondarily noticed (Husserl, 1998: 52). Within the ever changing of experience (mainly actual) and its articulated levels of clarity, distinction and interest, attention can keep the intention throughout the flow of experience and within the "changing field of noticing [Bemerken]": "We have the capacity to convert each incidentally noticed thing, at least for a moment, into something noticed primarily, therefore into something distinct. (...) It is the case that the change of content that takes place when something distinct becomes indistinct or vice versa is a continuous one (...)" (Husserl, 1991: 151). Within this field, attention acts and reacts, with a characteristic freedom, to the intentional objects and the stimuli operated by affection and interest. Thus, what primarily distinguish noticing and attention with its focal point and levels of increasing clarity and distinctness, is a certain "being inclined" of the subjectivity and a specific intention which is favoured by attention and tends to lead to fulfilment ${ }^{14}$. By coupling with the sense animating apprehension specifically, attention is based on it and anchored to the complex of intentions constituted waiting for fulfilment, while it let arise a favoured direction of the intending. This occurrence results even in the prevalence of the present presentation [Vorstellung], that is, with reference to other presentations temporally displayed or within the same living present.

Now, the latter characteristic seems to conflict with another, apparently. Namely, in the introduction we remember Husserl's referring to the synthetic power of attention as exposed in the Philosophy of Arithmetic. Husserl describes the fundamental "ability" of attention, which refers to more than one presentation at the same time. This power appears phenomenologically in all its evidence when we reflect on our ability to establish references, to confront etc. more than one presentation within the same act. Moreover, attention has the function of keeping the regard towards the object in the focus of our experience and interest, and "according to the sense by which it is experienced" and intended (Husserl, 2004: 30, 122). This last observation opens up the complex Husserlian exposition of the relationship between attention as meaning and object intended, stressing yet the fact that attention (i.e., the specific meaning) does actually vehiculate a form of specification in the

14 On the relationship between noticing and attention, see Breyer (2011: $217 \mathrm{f}$ ). 
apprehension and intention while it maintains a complex meaning in a unity, allowing the experience of the Objective "new", the change by grasping an object or objects, that depends on the formative and preferential function of attention. According to our interpretation of Husserl's description, this specifying of meaning is important for understanding image-consciousness, as we will see. But before going deeper into the analysis of image-consciousness and phantasy, we must first clarify the character of attention which makes it, from another point of view, an all-encompassing modification.

\section{Plasticity, meaning, and interest}

Having exposed these general traits of attention, which Husserl will partially maintain throughout his entire phenomenology of lived experiences, we can now introduce a more specific property of attention that is relevant for understanding how the attentive modification is at work and can be at work not only in perception but importantly in phantasy and image-consciousness. This property we want to stress can be labelled the "plasticity" of attention. With such a term (never used by Husserl) we mean the attention property of fulfilling and serving its function in all kinds of experiences, from perception to memory, phantasy, and image-consciousness, without changing the mode or character of the act but still introducing a decisive difference in the intention of the object. This property is introduced by Husserl by asserting that the concept of attention embraces the field of intuitive and cogitative meaning, of presentation as intuition and thought, and that the "certain selectivity", which indeed embraces all spheres of consciousness as a "certain difference" within the particular lived experience, "(...) is not dependent on the species of our mode of consciousness or its manner" (Husserl, 2001: 275, modified).

Attention is, first of all, independent from the kind of object meant by the act and even, within certain limits, its number, as well as from the nature and characteristics of the content. In the Philosophy of Arithmetic Husserl criticises a false interpretation of the psychological concept; the "narrow range of consciousness" 15: "It is true that the number of separate contents to which we

15 Husserl already spoke about the narrow range of consciousness in his 1887 Habilitationsschrift "Über den Begriff der Zahl", but the topic would not assume more importance until 1898 (See: Husserl, 1970: 333; Husserl, 2004: 98) 
can turn our attention in any one moment is highly restricted. (...) But it is false that we can never be engaged with more than one content in one and the same moment. (...) If in every instant only one content is present to our consciousness, how should we be able to notice even the simplest of relations" (Husserl, 2003: 27). In the case of the comparison involved in the formation of a multiplicity, for example, "we concentrate attention upon the constituents to be compared, abstracting as far as possible from the properties that differ" (Husserl, 2003: 108). Surely, in the Logical Investigations Husserl excludes that attention is directly responsible for the abstraction involved in the formation of complex cognitive objects. But the two aspects of attention mentioned above, i.e. meaning and interest, are surely involved in the differences in the grasping of objects on the basis of the same apprehension. This function is already present in Husserl's 1892 work on arithmetic. Attention and interest enter into the formation of different kinds of representation, in the case of physical parts belonging as "properties" to the whole of an object, or when we speak of a "group representation", by which "(...) their combination within the intuition of the whole recedes into the background" (Husserl, 2003: 207). Attention and interest are therefore involved in the object differences emerging within the "same" object of apprehension.

Another aspect, aforementioned, of such plasticity and relevant for interpreting attention in our context, is the non-doxical character of the attentional meaning. That is, the meaning of any object is not a doxical act and does not imply a doxical position, and that also goes for the phantasy object, the object or subject of image consciousness and, more generally, also for all kinds of representational objects. Although the "meaning" is naturally coupled with the concept of doxa (and Husserl does not directly deny such conceptual likeness), the general position of the quality of acts [Aktqualität] depends on apprehension: "the meaning turning-towards [meinende Hinwendung] is, for itself, still not take-for-existing nor for-no-existing" (Husserl, 2004: 83). The attentional meaning moves within the experiential "space" granted by apprehension, figuratively speaking. The meaning turning-towards is carried out through attention and does not, therefore, alter the original doxical position of the object meant, which is granted by the original position of apprehension (Cf. Husserl, 2004: 371). Attentional meaning and quality must be "distinguished" and all the possible "variations of meaning are not to be 
identified with the variations of the qualitative characterization as being, not being, doubtful etc." of the act object (Husserl, 2004: 123). The variations of quality in following the experience are independent of the variations of meaning, while these latter variations $d o$ produce variation in the intention of the object. "The attentional directedness-to, the intentional look, results in «S is p»", which is thus characterized as existent, not existent etc. by subsequently taking a position in the unity of act (Husserl, 2004: 372).

The reference to the variation of meaning now needs clarification, which may help in the understanding of the relationship between the meaningintention and the object. First of all, Husserl develops his view on meaning following the increasing complexity of his intentional analysis of acts. In the early years of his investigation on mathematical concepts, what was truly "intended" [gemeint] in this sense was the object of a conceptual representation while, in the intuitive representations, the object appears directly or through an image ( $C f$. Husserl, 2003: 83). In around 1898 the early phenomenological description also contemplates the complexity of intuitive experience. The meaning is now described with its special functions already in intuitive experiences, that is, also where we find a perception object with an implicit ideal possibility of the perception of its "determinations" unrelated to conceptual representations and on the basis of the same apprehension (Husserl, 2004: 69). The meaning plays a role in the grasp of the intentional object thanks to a specification; a selection or a preference of the intention by which the object is experienced, as we have seen; but now, Husserl stresses how it is the meaning that makes all the "incredible differences" possible by the grasping of objects in intuitive consciousness, on the basis of the same apprehension and within its unitary intention (Husserl, 2004: 78). In the unitary apprehension, meaning shows the tendency, aiming at the "intentional object", or rather, it belongs to the structure of an act while it specifies the intention within the range of possibilities constituted by apprehension for all modes of consciousness. The direction towards the object orients the focus of attention with its halo of less attentive contents waiting to be explicitly grasped and calling for the "turn towards". The attentive meaning of an object thus involves, at the same time, to "abstract from something" or "to overlook" something while we are effectively "looking at" it [Hinsehen] or "assuming it in our regard" (Husserl, 2004: 77). Thus, these two aspects are connected to the interest, for "elements 
that in certain conditions call for our interest, later on, are not held to be valid by us" according to our interest (Husserl, 2004: 78). Consequently, the meaning turning towards is explicitly associated with the act of considering according to Husserl. This is "still not in itself a taken-for-true [Wahrnehmen] nor for-false [Falschnehmen]" and does not result in a modified translation to other kinds of acts, while the act of object grasping is "yet evidently not the same as the sense" according to differences in the meaning (Husserl, 2004: 78). We consider the object of the objectivating act differently, depending on what is primarily intended [gemeint], the direction of our considering and, finally, what is cointended. The differences in the consideration according to the meaning are proper for all objectivating acts. In fact, "we can also observe $<$ the same $>$ in other species of objectivating phenomena, for example, in phantasy representations". Thus, Husserl descriptively introduces distinctions by the meaning, like the "particular", the "secondary", the background, and even a negative meaning (Husserl, 2004: 120-121). While we are primarily intending [meinen] the object, it is present in itself and normally the object of interest. However, we can also experience the object (or objects) while another one, or a moment of it, "is additionally co-assumed". Or, while we are positively directed towards it, another object is excluded, dismissed, but, still, constituting what is properly intended. As a result of that, Husserl also refers to clear presentation [Vorstellen], which "the implicit meaning belongs to, that delimits the objectivating apprehension". Yet, the meaning unity remains characteristic of the multiplicity of possible apprehensions and all the components belonging to its totality with the intentions and, respectively, the presentations, are "fused" and involute in it (Husserl, 2004: 121). As a result of the description, Husserl stresses that "the objectivity in the sense of our lived-experiences exceeds over and above the circle of that, what is positively intended [Gemeinte]". Along with "the objectivating and delimiting meaning, which brought objects as things for themselves to appearance", we find the unlimited meaning. Yet both are intimately connected, they are one and the same thing. Moreover, the separation participates in the intuition of the object as a necessity: what it is delimited, singled out, defines that, what is separated, while, evidently, "separation is also a form of unity" (Husserl, 2004: 122).

Eventually, Husserl implies the concept of "specific meaning", which couples in the phenomenological description of perception with the early 
reference to the horizonedness of all kinds of experiences, spread in Husserl's philosophy after the consideration of time consciousness in the same 1904 lectures (Husserl, 2004: 69). The object in regard is, in its unity, the fusion of partial intentions that are not actualised. Meaning and proper intention are now the patent orientation within the context of experience and the actualisation of intention among the co-intended ones on the basis of the same apprehension and content. Such intention can be voluntarily distinct and can follow our interest, or can emerge due to a qualitative pre-eminence, but it is also relatively independent from its sense contents. Therefore, the meaning not only gives something to the object in general but also a certain characteristic; it "is the new, to which the different 'form of consideration' of the object has to be linked" (Husserl, 2004: 74). Meaning may be driven by interest, but the latter has to be distinguished from meaning and attention, even though it is intertwined with both - as we have already introduced.

Traditionally, and especially in late $20^{\text {th }}$ century psychology, attention and interest are, in fact, closely related. A clear example of such a connection is offered by Carl Stumpf's study in the Tonpsychologie, where interest is related to attention and desire or delight (Stumpf, 1890: 280). Husserl even recalls the connection between interest and attention, slightly criticising Stumpf's conception of interest and its definition as the "pleasure in noticing" or observing (Husserl, 2004: 159). Surely, according to Husserl, interest is a power that moves the observation or noticing, like in the case of something that attracts attention from the field of what is more or less clearly noticed (Husserl, 2004: 108). When Husserl speaks about interest, he normally refers to what he calls "theoretical interest", which is interest at work in the process of reaching evidence in object perception (Husserl, 2004: 115) ${ }^{16}$. Therefore, it was an easy step for Husserl to connect and, at the same time, to distinguish interest and meaning: In fact, the former shares the function of preference and circumscription within the sphere of the noticeable with the meaning. But it also implies differences in intensity, a quality not shared by meaning. Our interest may be more or less intense according to our willingness and desire, while the meaning of an object does not show such variation of quality. Moreover, interest has an emotional basis, which also distinguishes it from

16 On interest, especially theoretical, in phenomenology, see Lee (1993: 183 f). 
intention. Husserl defines interest as an "emotional act" [Gemütsakt], which manifests a certain intensity, even when it is close to zero, while the objectivating meaning does not manifest such intensity (Husserl, 2004: 118). Besides, interest may be satisfied, while meaning can only confirm itself or change the experiential process. Having said that, the intensity of interest participates in the definition of the "range of living presentations", that is, interest co-defines the extent of presentations brought together (or separated) by attention (Husserl, 2004: 99). Thus, for Husserl, the theoretical interest will always have such characteristic, "to be directed ultimately towards knowledge of the totality of that what exists", stimulated by affection and within the sphere of givenness of all kinds of experiences (Husserl, 1973: 31, modified). ${ }^{17}$ Interest as attention does not depend on the kind of object brought together, nor their ontological status. For example, "on the basis of a full perception which intends something apprehended, an interest takes place, an interest in the object, i.e., in its development of the cognition. Thus, on the basis of the same perception, there is no need for a believing or not believing to take place, even if it can happen" (Husserl, 2004: 123, italics mine). Years later Husserl would repeat himself on this point:

The aesthetic interest aims at the presented object in the How of its presentedness, without interest in its existence itself and in its quasi-existence. In the case of the beautiful landscape that I am actually seeing, [my aesthetic interest aims] at the landscape presenting itself from here, from this entrance to the valley, just as it presents itself (Husserl, 2005: 704).

The plasticity of attention is also manifested by interest, which for itself is, again, no taking position with respect to the being or non-being of the object considered.

Besides this brief distinction between interest and meaning, in 1904/5 another aspect of particular importance for us emerges: Husserl refers to another kind of interest, i.e., the aforementioned "aesthetical interest". In the following quote from the third part of the lecture on Memory, Phantasy and Image Consciousness the difference between mere theoretical interest and

17 See also Wehrle (2010b: $167 \mathrm{f})$. 
aesthetical can clearly be seen:

In aesthetic contemplation, we immerse ourselves in the image; our interest belongs to it, we see the subject in it. (...) Naturally, I do not wish to imply by this that interest and meaning belonging to the aesthetic image is directed exclusively toward the subject as if it were always only a matter of bringing the subject to intuitive presentation (Husserl, 2005: 39).

If interest was mainly directed towards bringing the object, or the subject (in the case of image consciousness) to a more complete or particular presentation, the aesthetical would be identical to theoretical interest. Yet by aesthetical interest, we do not pursue new presentations, like in the case of having better knowledge of the subject, "on the contrary, interest always returns to the image object and attaches to it internally, finding satisfaction in the manner of its depiction" (Husserl, 2005: 40). In these passages, Husserl introduces a peculiarity of the kind of lived experiences, which is what phantasy and imageconsciousness are, and these force us to look at the specific role of attention in the form of meaning and interest by them very closely. As we shall see now, both participate later extensively in what makes such re-presentation what it is. Thus, attention participates in the constitution of both kinds of experiences, but also in the constitution of the proper aesthetical experience. Aesthetical enjoyment evidently has to do with interest, meaning, and their roles, while it can concern a variety of different kinds of lived experiences and objects. For example, "one can also enjoy one's phantasies aesthetically and contemplate them in an aesthetic manner". "Then", says Husserl again, "we do not merely look at the subject in image consciousness; rather, what interests us is how the subject presents itself there" (Husserl, 2005: 40).

\section{Attention in phantasy}

According to Husserl, phantasies are intentional and objectivating lived experiences. While they share some features with the perception they also differ from the latter as regards some important aspects, which are relevant for the study of attention in this kind of lived experience. The most striking difference, that we know of, is that perception and phantasy belong to two different kinds 
of lived experiences: presentation and re-presentation [Vergegenwärtigung] ${ }^{18}$. A difference that can be traced back to the manner phantasy, in general, which offers its object, i.e., "in phantasy (...) the object itself appears (...), but it does not appear as present. It is only re-presented; it is as though it were there, but only as though" (Husserl, 2005: 18). Objectivities are brought to appearance in phantasying and eventually meant (gemeint) - for example, a minotaur — in this or that way. Thus, such a kind of lived experience belongs to the objectivating and intentional acts in a different way to perception, but Husserl approached phantasies phenomenologically in the same manner as perception during the 1904-5 lectures. In fact, in his analysis of all kinds of lived experiences around this time, Husserl was still (already problematically) using the so-called "apprehension-content schema" for interpreting the relation between content, object, and intention. However, this very approach gives us the possibility to stress the proper function of attention in phantasy; that is, not only because of the synergy of the function between attention and apprehension already seen. Phantasy apprehension cannot be identified with perceptual apprehension, but the concern for Husserl is that many distinctions are descriptively common in both acts. On the one hand, the distinction between apprehension, meaning and the so-called "qualitative deciding" based on apprehension (Husserl, 2005: 17); and on the other hand, the distinction belonging to the structure of apprehension, between the content, the object and its sides or adumbrations.

Besides some extremely difficult questions about the content's nature of phantasy, i.e., the phantasms, the descriptions made by Husserl in the framework of both aforementioned distinctions make it possible to allow the emergence of the way in which attention as meaning works with respect to the object. Surely, the object itself appears in the case of phantasy, but it does not appear as "present in person". In phantasy the object is inactually given, hovers before us, and even if it resembles perception, phantasy is perception "as if" (Husserl, 2005: 34, 405). This definition of the phantasy object is partially due to the nature of this act, which is "an inventive rather than a positing act" (Brough, 2005: XXXVI). The characteristic of actual existence is not something that can be invented by being directed precisely against actual or factual

18 I will follow the translation of Vergegenwärtigung as re-presentation. 
existence and by depending on the character of apprehension (Husserl, 2005: $665,673)$. The act character and the characterization of the object as perceived or phantasied depends on apprehension. But now, the phantasies that we ordinarily experience are not pure phantasies. Instead, they are acts in which we phantasise "a figment into a portion of intuitively experienced reality" (Husserl, 2005: 610). Thus, we phantasise something as inserted into the perceptual field. However, the phantasy object and what I perceive, for example (my perceived surroundings or other object in the background), "don't truly melt one into the other" (Husserl, 2005: 83). If I focus on the object of perception, my phantasy object disappears or, at least, fades into the background and vice versa: "I cannot become absorbed in both simultaneously and I cannot include both in the same intention" (Husserl, 2005: 179, note 3). This modification in the focus is to be linked with attention and, more precisely, with the meaning and the selectivity or preference in the intention dominating the act. With the intention the act character plays its role in the experience while the meaning of the object does not result in a modification of the former. For example, the conflict which can be generated by a phantasied object among perceptual objects on the basis of a perceptual background, depends on the intentions. A peculiar conflict exists as long as "I want to interpret a phantasy image as existing in the visual field of perception": "If I phantasise a line as on this piece of paper", for example, I thus "experience empirical conflict", at least, as long I interpret the line with the character of the paper's existence (Husserl, 2005: 179).

A more common phantasy we can experience is less "conflicting" than the previously mentioned case, which is closely related to hallucination due to the conflict of position. What is now a case of a normal phantasy or even a kind of "representing in image" 19 offers a different intentional description:

If I represent the children's room, this representation does not conflict with the perception, although I cannot simultaneously hold both in truly intuitive vitality. (...) While I am presenting some painting, to myself, the perception of the visual field does not disappear. However, I cannot become absorbed in both simultaneously and cannot include both in the same intuition. And I can,

19 Cf. Husserl (2005: 327). 
in any event, maintain the intentions aimed at both undisturbed (...). These are compatible, not incompatible (Husserl, 2005: 179).

Belonging to the same experience we find a complex of intentions which are compatible with one another, but not emerging with the same vitality. The intention aiming to the object I am now phantasying and which is overlapping the perceptual field is the attentional focus of my experience. As long as I am directed towards such an object, the prevailing intention does not change, while the perceptual background competes for the foreground. Yet already these few observations lead us to the characteristic description of another presentation mode fundamental to phantasy:

In every instance of such presenting we distinguish between image and subject. The subject is the object meant by the presentation. And subsequently and by virtue of qualitative characteristics combined with it (intellectual or affective characteristics), this object is the object taken to be existing (e.g., the remembered or expected object); or the object taken to be unreal, as in the fiction known to be fiction. (...) We now disregard these characteristics; we must retain only the act of meaning. (Husserl, 2005: 19)

The meaning is the act thanks to which we have the subject already presenting the image. The quality that qualifies the subject as existing, existed and so on, arising from the act basis is not dependent on the meaning. Meaning evidently plays its role alongside the ontological status of the subject. However, with the only constitution of appearance, the specific relation to the image subject in the case of image consciousness is still not clear. But the description in the general case of apprehending in phantasy implements elements in the description of the meaning. This apprehension interprets the content and confers on it it's relationship to something objective and that by "presenting something with content, the meaning (...) of something by means of the content" (Husserl, 2005: 24). The relationship between apprehension and meaning is therefore clear: "To produce an act of meaning on the basis of this apprehending and to be related in the meaning to the object are again one and the same" (Husserl, 2005: 24). As we have seen, the meaning "delimits" the specific objectivating apprehension. With a simple apprehension we have the object functioning as an 
image.

But descriptively it is now interesting that "the portrait is taken by us to be an image; that is, we do not mean the image object appearing chiefly in shades of grey or even a painting's image object appearing in colours". We experience the image object directly as the image of something else. In this case, a "bare act of meaning cannot be of help" because phantasy apprehension differs phenomenologically from perception, in which the object of apprehension is the object intended [gemeint]. In phantasy presentation we have, in fact, two apprehensions, one built upon the other which constitute two objects: the phantasy image that appears on the one hand and, on the other, the image subject which is presented pictorially, and which is presented precisely by means of the image. Husserl clarifies, therefore, the relationship between apprehension and meaning in the case of a phantasy presentation: "The meaning belongs to the complete phantasy presentation, (...) and is directed toward the image subject" (Husserl, 2005: 25). This second apprehension imprints a new character to the lived experience and gives it a new object relation. The act of meaning is then directed not simply towards the image object by itself but towards what is represented. Phantasy presents an object above all by making another object appear which resembles it and by taking it as the representative, the image stands for the object genuinely intended. "In the image one sees the subject" and one lives totally in the new apprehension that grounds itself on appearance (Husserl, 2005: 27). Image consciousness functions as such on the basis of the characteristic of representation according to resemblance, and that goes in the case of the phantasy contents, as well as for the physical image apprehension, or perceptual representation, the representation in pictorial exhibiting. This early interpretation of phantasy acts in the form of "imagination (...); specifically, as immanent image presentation" will be criticized in the 1904 Lectures and abandoned by Husserl in the following years (Husserl, 2005: $59 \mathrm{f}$ ). However, some fundamental features of this description will be present also in the more difficult case of perceptual representation. Before we go further into analysing the even more complex case of the image experience on the basis of a physical image, another function of attention in the sense of a meaning turning-towards in the case of phantasy is relevant for us: the intentional "structuring" (or orientation) of phantasy operated by attention. 
Husserl is certainly well-known for his description of perception in the sense of, on the one hand, a "system of referential implications" where we find an "appearance-core upon which appearances have their hold" (Husserl, 2001b: 41) and, on the other hand, of a "multiplicity in a unity", that is, as a complex stratification of less and less attentive contents around the focus, the "fixpoint" established by attention (Husserl, 1979: 278). With the distinction between a core of activity and the connected and surrounding halo of passivity, Husserl also achieves a description of the dynamic and multi-layered interplay of the foreground and background of experience. This description reaches particular importance in Husserl's phenomenology of perception in around 1904, as we have seen. The description of the horizonedness in the case of perception is well-known, but Husserl also applied a closely related description of Phantasy, at least, concerning the function of the meaning. Husserl wrote the following in a manuscript from his early years in Halle:

If I represent a lion, then in my phantasy it is as if the lion were standing there facing me in the surroundings that belong to it or that are represented along with it. The meaning turning-towards aims at the represented lion, but I am "co-represented" and so are the lion's surroundings. Am I also co-represented as perceiving the lion in its surroundings? This too is incidentally corepresented. The meaning turning-towards can therefore be directed towards all of these matters. If we call the turning-towards "presentation," [Vorstellung] then, of course, only the lion is presented. (Husserl, 1991: 165)

The meaning can turn towards the surroundings or other objects within such surroundings. When the attention as meaning turns directly towards an object the consciousness intends the object through all the presentations. In the case of phantasy, the turning towards is also an eminently inventive act which can labelled as a presentation in a different sense to the "proper" presentation of noticing or observing, which is the "simple assumption of a content" or "to be simply turned towards it" (Husserl, 1979: 278). By the perception to attend means a preference within the sphere of noticing, while the case of phantasy appears phenomenologically more complex because of the more direct relationship between the "presentation" itself and the meaning turning towards. Yet in many respects we find similarities. Phantasy is an inventive act with a 
certain grade of arbitrariness but has its own kind of harmony. It creates a harmonious world for the centaur, exactly like the harmonious constitution of the perceptive world. By the perceptive horizon, we find the explication of attention, which allow the different object experienced to emerge according to the interest, the changing contents etc. The "quasi-explicating" that opens up the horizon of phantasy's quasi-world "is a new and free phantasying-in" connected with the focus of attention in its changing and progress (Husserl, 2005: 642). However, any explication performed within the sphere of perceiving results determined to a certain extent, whereas in phantasy the meaning can follow its own determining force. In phantasy, attention and meaning establish the "point of view", the starting point of the perspective from which we see the object and subject decisively; and at the same time, attention freely establishes the point by which the image subject is primarily presented and the act subject, that is the phantasying ego, is "co-represented".

\section{Attention in image-consciousness and pictorial experience}

Besides the form of re-presentation represented by phantasy, Husserl notoriously offers a further basic description of the perceptual re-presentation in his 1904 Lectures. Perceptual re-presentation is basically a form of representation based on a special kind of perception, i.e., the perception of a work of art (in a very wide sense that comprehends portraits and photography) and which consists of what Husserl usually calls image consciousness. Even if image consciousness deeply relies on its constitution on a mere and straightforward perception, phenomenologically differs profoundly from ordinary perception. The most striking difference is surely the fact that while perception is normally animated by a single intention directed towards a single object, image consciousness is a more complex intentional act. It actually involves as many as three objects: first, the physical support for two other objects, a physical object which is called the "physical image", which is normally identifiable with a portrait, a photograph, a canvas in all different materials, shapes and colours; second, the representing or depicting object, the so called "image object"; and third, the represented or depicted object, that is, the "image subject" (Husserl, 2005: 19f).

Among the three objective components of image consciousness, there are 
certain important differences. The image object is not a part nor an aspect of the physical image, namely because its qualities can differ from the ones belonging to the image object profoundly. If we look at Van Gogh's 1889 selfportrait, qualitatively the characteristics of the object "Van Gogh's portrait" are different from the image object "Van Gogh" summoned by the colours, shapes and material of the canvas. Evidently, both objects differ, by their part, from the image subject, that is, from Van Gogh appearing in the image. In the first place, Husserl puts a great deal of effort into establishing the difference between the image object and the image subject:

it belongs to the essence of the imaginative apprehension from the beginning that, while this object colored violet grey appears to it, it does not mean this object, but a different object that only resembles it. From case to case, and depending above all on the kinds of depiction, the differences between representing image and image subject, between the object that genuinely appears and the object meant and presented by means of it, are quite diverse and vary a great deal." (Husserl, 2005: $21-2$ )

This long quote is important for our study, as it relates to the role played by apprehension in the case of image consciousness. On the basis of the perceptive apprehension animating the portrait's contents, the intentional act at play "means" another object, i.e., the image subject. Thus, apprehension and meaning are fundamentally connected to experiencing an image as such in image consciousness, exactly like in the case of a phantasy presentation. In addition, however, the role of attention in image consciousness is connected to the awareness of a peculiar conflict. In particular, a consciousness of difference must be present, says Husserl, even if the subject does not properly appear. In fact, the appearing object is not just taken by itself, "but as the representant of another object like it or resembling it" (Husserl, 2005: 22). In order to have image consciousness there must be resemblance and difference between the image object and the image subject. Moreover, if we are experiencing a pictorial image, we immediately feel the image to be an image. Husserl tried to make sense of such a peculiar awareness of image consciousness by looking, once again, at the resulting role of apprehension in the special case of the perception of an image. 
As Husserl stresses in the case of images, the apprehension based on sensuous sensation is not a mere perceptual apprehension, i.e., there is not merely a perceptual apprehension animating the sensuous contents belonging to the portrait and its surroundings. Another apprehension besides the simple perceptual apprehension is needed, otherwise there will be no image consciousness. We are speaking about a resemblance representation, as a new mode of apprehension. In fact, this proves the relationship to the image subject. The second apprehension is not something external to the former, the new apprehension permeates the old one. The apprehension and the image object make intuitable what is not identical to it but is more or less like it. But through the simplest depictive consciousness it already begins to emerge, firstly, the difference consciousness:

If the appearing image were absolutely identical phenomenally with the object meant, or, better, if the image appearance showed no difference whatsoever from the perceptual appearance of the object itself, a depictive consciousness could scarcely come about. This is certain: A consciousness of difference must be there, albeit the subject does not appear in the proper sense. (Husserl, 2005: 22)

Moreover, a peculiar conflict couples with this conscious difference emerging, as such, in the image experience. This is a conflict between the apprehensions involved in the perception of a physical image. While we are perceiving the image as such, we live in the "continuously united apprehension pertaining to our field of regard", determined by the focus of attention in the appearance of the image object. But the paper apprehension "is present in a certain way", except that it is, itself, not an appearance. Its apprehension contents are now functioning as the apprehension contents of the image object only, “(...) it belongs to these apprehension contents: in short, there is conflict" (Husserl, 2005: 49-50). As long the image object comes to appearance, it triumphs over the appearance of the paper, or the physical image's the shades of colour. These contents are in fact fully used by the image-object apprehension. But the paper apprehension still has its stable connection with the appearance of the surroundings, only it does not come to the fore as such.

The image comes to the fore in noticing particular details that are 
fundamental to the physical image. Yet already in noticing they are also set apart from the other traits of the image object. Such traits emerge in the sphere of noticing, where the content and the apprehension imply determinancies and indeterminancies which, firstly, make the intuition of the image subject possible in the conflict with the corresponding determinations that belong to the subject meant, while, at the same time, such determinancies and indeterminancies leave open, or exclude, how it would be intuitive on their bases. Of course, such conflict depends partially on the peculiar sensitive contents apprehended, which are intentionally arranged for the image, yet also on the apprehensions themselves with their intentions. The structured intentions on the basis of the unitary perceptual apprehension makes the necessary contrast for the image consciousness possible, or, as Husserl says: "The different intentional contexts into which the subjects fit produce a conflict of consciousness. They prevent an unmodified, simple object-intention from becoming constituted" (Husserl, 2005: 34). The latter is typical of perception, but the image subject becomes intentional in a peculiar way, and the conflict implied relies, ultimately, on the attentional meaning:

The apprehension that constitutes the image object is at the same time the foundation for the presentation that, by means of the image object, constitutes the other object; and in normal phantasy presentation and image presentation, the act of meaning is aimed at the latter, directed towards it alone. This second object is intended in a quite singular way. No appearance corresponds to it. It does not stand before me separately, in an intuition of its own; (...). It appears in and with the image, precisely because the image representation arises" (Husserl, 2005: 29)

Essentially, only the functioning act of meaning allows the image subject to be maintained as intended, and the difference with it, in the duality of apprehension, remains ever present. The differing function of meaning is then connected by Husserl to the change in attention, on the base of which the privileging act of meaning comes to fore: "several essentially different apprehensions showed themselves to be based on one another or in one another, corresponding to the number of objectivities that are produced and, depending on changes in attention, come to the fore for the privileging act of meaning" 
(Husserl, 2005: 30). Attentive meaning is privileging a specific intention, which is surely structured in a complex act. In fact, it implies in its unity the intention of the object and what is co-intended, which may not be explicitly meant, but it contributes to the totality of experience. What is co-intended but not especially meant is everything that composes the "field of view of perception", within which the ego experiencing the picture is also co-intended, even if it is completely absorbed in the pictorial experience (Cf. Husserl, 2004: $88 \mathrm{f}$ ):

While we are living in the imagining of the subject, the visual field of our perception does not disappear. On the contrary, we have the perception of our surroundings, even if not in the form of a primary act of meaning; and they are the surroundings of the picture, indeed, in a certain way, even of the subject." (Husserl, 2005: 49)

The difference in the kind of experience that we are living relies on the direction of the meaning by changing attention. A change in the direction of the meaningintention also signifies a change of object or the explicit meaning of the subject, instead of the image object, and vice versa. But there can also be a change in the direction towards the sensuous or imaginative components of the appearance. All this represents the possibility to turn our attention towards the manner of appearance of the image:

If we live in free phantasies or in memories, the act of meaning (...) aims at the image subject. But we can also focus our attention on the image object and, in turn, on the manner of its appearance, on the constitutive components of the appearance, and so on. (...)

The apprehensional basis can be precisely the same in both cases. The same image objects appear, and $<$ these $>$ are the basis for the same relation to the distant lands. In the one case, however, it is the image objects that are meant and are the focus of interest; in the other case, it is the distant lands. (Husserl, 2005: 39)

These are the possibilities of specific meaning, but they become important due to the arising of image consciousness itself; that all the apprehensions involved in the act are not "separate" but "interwoven", and only a reflection on the act allow the distinct unities to emerge (Husserl, 2005: 28). By the normal image 
consciousness (and phantasy) the meaning becomes immediately directed to the image subject. A physical depiction is primary experienced only as a depiction. Due to the change in the direction of attention, it is possible to mean even its physical support. It is also worth stressing that the unity of such an experience prevents us to interpret the attentive meaning of subject and object in the form of an active relation-consciousness, especially when we think about the aforementioned difference consciousness. The change in the attention only allows all the differences to emerge, while the meaning "goes through" "all the presentations", establishing what it is explicitly intended and pushing what is co-intended but still determining the entire image consciousness into the background. This change can result from interest, and in the case of an image (but not only), the attention may turn towards the manner of the object appearing or "how" the subject appears (Husserl, 2005: 40). In this case, attention as interest conveys a "living in the aesthetic feeling", which means, firstly, "the turning toward the manner of appearing, which thereby gains a distinctive mode", and secondly, a "thematic primacy" (Husserl, 2005: 464). A judgment, an aesthetic one, would then arise as a result of a later activity. But by now, interest is "sensuous" interest, which has no theoretical purpose in being "delight in the appearance". "Hence", as Husserl says, "this is already a question of aesthetics" (Husserl, 2005: 168).

\section{Conclusions: attention and aesthetic experience}

In our exposition, we saw how the meaning is essentially connected to apprehension and intention. The aspects of preference and selection of attention came to the fore, in particular, with respect to the intention and the object intended. A "change in the direction of the meaning-intention also signifies a change of object" as the result of the "objectivating act of meaning". All the different acts of presentation are constructed "on the same apprehensional basis", but, "to mean the image object, to mean the image subject, and again to mean the image object as the image of the subject are different objectivating states" (Husserl, 2005: 41). Two objects cannot "stand out" in their appearances simultaneously on the basis of two apprehensions and the same contents. Attention, indeed, keeps together the experience while it performs the modification of direction by segregating certain elements of experience while 
privileging others. The selectivity of meaning "structures" the experience with the intention of the object brought to appearance, along with the intentions not actually specified. By means of that, attention can also connect more than one presentations at the same time. Attention is not, eo ipso, an explicit act of synthesis. The result is only a specification of intention by maintaining the cointended, not only of the perceptual horizon of image or phantasy. The meaning "holds" the intention directed to the image subject, while keeps the appearance of the image object and the possible intention directed towards it, or the physical support, in the same field of regard. Thus, we have the meaning of different objects, for the objectivating act is different, while we still have the same appearance. The appearing "thing" remains the same. "It is in the particularity of the meaning and not in the particularity of the 'thing', which remains unmodified, that the new appears to base on" and to which the different "form of consideration" concerning the thing has to be linked (Husserl, 2004: 74). Surely, "in physical image contemplation we do (...) have conflict in the perceptual field of regard. There, two intentions overlap". The attentive meaning does structure the intentions by specifying the perception while holding the co-intended in unity. By means of that, attention promotes the peculiar conflict exposed, essential to image consciousness. In phantasy, we can have the same kind of depictive image consciousness "mingled with conflict", or "the phantasy meaning can be directed toward the thing itself", resulting in a "direct consciousness of the object", although in the form of "something not present" (Husserl, 2005: 193-194). In this case, the meaning simply couples with the phantasy apprehension and its positional modality ${ }^{20}$.

The fact that the meaning does not imply, for itself, a modification of the "positional modality" of the object of intention seems important in phantasy and image consciousness, but even more in the aesthetic experience. The meaning of the object does not modify the act-quality. We can be directed, for example, towards the object of a hallucination, which is, in the meanwhile, not recognized as such. Notoriously, Husserl presents in the $\S 111$ of Ideas I some ideas on the "neutrality modification of normal perception". According to Husserl, image object and image subject are neutralized, that is, in aesthetic experience we are not interested in the existence or non-existence of the

$20 C f$. Husserl (2005: $197 \mathrm{f})$. 
depicting image object: it is present to us in any "positional modality" (Husserl, 1998: 260-262) ${ }^{21}$. The non-positional modality couples well with the image object, which can be eventually intuited, in one of its sides, in the form of a perceptio [perception] as a form of "aesthetic appearance" — that is, a perception without the doxical position of perception [Wahrnehmung] (Husserl, 2004: 209, 358). In the case of the image subject in image consciousness, although it can not be properly perceived, the existence or not existence of the subject represented may play a role instead (for example, in the case of a documentary). From the viewpoint of meaning, the fact that the latter does not imply for itself any existential position allows the peculiar "suspension" which characterizes aesthetic experience (Husserl, 1994: 134). This does not prevent us from having, anyway, the following object intention permeated with a doxical character, i.e., the "particular perception" of the work of art.

In the case of phantasy and image consciousness, we saw, the attentive meaning can return to the manner of appearance of an object. The meaning is driven now by the aesthetic interest. Thus, attention and interest are at play in the "aesthetic valuation" as long as it is "connected with the distinction between the consciousness of an object as such and the object's manner of appearing" (Husserl, 2005: 461). Husserl stresses how "the consciousness of the image subject is present $<$ here $>$ too", and how it is essential for the "aesthetic image" (Husserl, 2005: 55). In fact, Husserl refers to the manner the subject appears as fundamental for establishing "how aesthetically pleasing the manner of appearing is" (Husserl, 2005: 40). We saw the connection between the attentive consciousness of the manner of appearing and the following "pleasure" or "delight". This consciousness is not limited only to the works of depiction, especially works of art, but appears also in the case of theatre, nature, or landscapes (Husserl, 2005: 619). Thus, besides the problem of the "subject" of aesthetic interest, from the viewpoint of attention the delight keeps aesthetic interest directed towards the appearance. "Different appearances of the same object are not equivalent in this affective direction", observes Husserl (Husserl, 2005: 168). The maximum stock of sensuous moments and their particular

\footnotetext{
21 The nature of such modification and its historical evolution in Husserl's phenomenology is a much-debated issue in the studies on Husserl's philosophy. See, for example, Brough (2005: XXXIX), Ferencz-Flatz (2009: 477 f).
} 
arrangement arouse delight, for example. Where Husserl speaks about delight and interest, he makes reference to the "rhythm of tension and release", which actually produces delight (Husserl, 2004: 160). This tension and release concern attention and perception. In particular, when a content or an object "calls our interest", a perception release the tension with a new content, for a particular perception supervenes. Due to its intentional reference, attention turns towards a new element in the field of noticing which calls, again, the interest. The constant rhythm generates delight in the experience and it represents its "motor" (Husserl, 2004: 108, 118). Also in the case of aesthetic interest, a "plurality of objects" calls our interest in the form of a unitary interest, by which an object (or content) is favored while the others "are still maintained". The interest for the objects represented on the one side, and the thoughts, comparisons, observations stimulated by the observing and noticing, generate the more specific "aesthetic pleasure" which can also be increased by the contrast of both (Husserl, 2004: 163). This kind of aesthetic pleasure is, sure, not always present in image consciousness and depiction, but it does help us to stress the double sides of our spiritual nature - the intellectual and emotional - which was, from the beginning, the core of Husserl's interpretation of attention as meaning and interest in his 1904-05 Lecture.

\section{Bibliography}

BÉGOUT, B. (2007). "Husserl and the Phenomenology of Attention". In: L. Boi, P. Kerszberg, F. Patras (eds.). Rediscovering Phenomenology. Phaenomenologica 182. Dordrecht: Springer, pp. 13-32.

BETTS, G. H. (1909), The distribution and function of mental imagery. Teachers College: Columbia University.

BREYER, T. (2011). Attentionalität und Intentionalität. München: Wilhelm Fink.

Brough, J. B. (2005). “Translator's Introduction”. In: E. Husserl. Phantasy, Image Consciousness and Memory (1898 - 1925). Edmund Husserl Collected Works XI. Dordrecht: Springer, pp. XXIX - LXVIII.

Clark, H. (1916). "Visual Imagery and Attention: An Analytical Study". The American Journal of Psychology, 27 (4): 461-492.

DePraz, N. (2009). “Introduction”. In: E. Husserl. Phénoménologie de 
l'attention. Paris: Vrin.

FERENCZ-FLATZ, C. (2009). "The Neutrality of Images and Husserlian Aesthetics". Studia Phaenomenologica, 9: 477-493.

Husserl, E. (2005). Phantasy, Image Consciousness and Memory (1898 1925). Edmund Husserl Collected Works XI. Dordrecht: Springer.

- (2004). Wahrnehmung und Aufmerksamkeit. Husserliana XXXVIII. Dordrecht: Springer.

- (2003). Philosophy of Arithmetic. Edmund Husserl Collected Works X. Dordrecht: Springer.

- (2001a). Logical Investigations. Volume I. London, New York: Routledge.

- (2001b). Logical Investigations. Volume II. London, New York: Routledge.

- (2001c). Analyses Concerning Active and Passive Synthesis. Edmund Husserl Collected Works IX. Dordrecht: Kluwer.

- (1998). Ideas Pertaining to a Pure Phenomenology and to a Phenomenological Philosophy. First Book. Edmund Husserl Collected Works II. Dordrecht: Kluwer.

- (1994). Briefwechsel, Bd. VII, Dordrecht: Springer.

- (1991). On The Phenomenology of The Consciousness of Internal Time (1893 - 1917). Edmund Husserl Collected Works IV. Dordrecht: Kluwer.

- (1989). Ideas Pertaining to a Pure Phenomenology and to a Phenomenological Philosophy. Second Book. Edmund Husserl Collected Works III. Dordrecht: Kluwer.

- (1988). Vorlesungen über Ethik und Wertlehre 1908 - 1914. Husserliana XXVIII. Dordrecht: Kluwer.

- (1984). Einleitung in die Logik und Erkenntnistheorie. Vorlesungen 1906/07. Husserliana XXIV. Dordrecht: Martinus Nijhoff.

- (1979). Aufsätze und Rezensionen (1890 - 1910). Husserliana XXII. The Hague: Martinus Nijhoff.

- (1973). Experience and Judgment. Evanston: Northwestern University Press.

- (1970). Philosophie der Arithmetik. The Hague: Martinus Nijhoff.

- (1956). "Persönliche Aufzeichnungen". In: Philosophy and Phenomenological Research, 16 (3): 293 - 302.

KÜLPE, O. (1902). "Ueber die Objectivierung und Subjectivierung von Sinneseindrücken". Philosophischen Studien, XIX: 508-556.

LEE, N.-I. (1993). Edmund Husserls Pänomenologie der Instinkte. Phaenomenologica 128. Dordrecht: Springer.

MARBACH, E. (1974). Das Problem des Ich in der Phänomenologie Husserls. Phaenomenologica 59. Den Haag: Martinus Nijhoff.

Wehrle, M. (2010a), "Intentionalitat, Interesse, Affektion - Das Phänomen 
der Aufmerksamkeit als Umschlagstelle zwischen Aktivität und Passivität”. In: P. Marz, A. Staiti, F. Steffen (eds.). Geist - Person - Gemeinschaft. Freiburger Beiträge zur Aktualität Husserls. Würzburg: Ergon, pp. 77-109. — (2010b). "Die Normativität der Erfahrung. Überlegungen zur Beziehung von Normalität und Aufmerksamkeit bei E. Husserl”. Husserl Studies, 26: 167187.

Mole, C. (2011). Attention is Cognitive Unison. Oxford: Oxford University Press.

STUMPF, C. (1890). Tonpsychologie. Leipzig: Herzel.

VONGEHR, T. (2010). "Présentation de l'édition Wahrnehmung und Aufmerksamkeit (Husserliana XXXVIII)". Alter, 18: 17-30.

ANDREA SCANZIANI completed his Ph.D. at the University of Milan. His research interests lie in the area of phenomenology, philosophy of mind, neo-Kantianism and contemporary German philosophy. He obtained his Ph.D. in Philosophy with the dissertation Type and Experience. The Origin of Ideality in Husserl's Early Phenomenology: A Critical Exposition of Husserl's Early Works in Halle and Göttingen, thanks to the financial support of the University of Milan. Andrea Scanziani has conducted researches at the Husserl-Archiv of the University of Köln and the University of Freiburg. His current work focuses specifically on Husserl's theory of attention and perception. He is the author of the Italian translation of Husserliana XXXVIII, Wahrnehmung und Aufmerksamkeit, published by Mimesis Milano in 2016. 